\title{
Do sistema educativo ao emprego. Formação: Um bem universal?*
}

\author{
Lucie Tanguy*
}

\begin{abstract}
RESUMO: Desde os anos 50, a relação formação-emprego vem se impondo progressivamente como princípio diretor das políticas educativas, acarretando transformações no campo do ensino técnico. Este artigo contesta a evidência dessa relação, sua progressiva naturalização e esforça-se por entender o paradoxo de uma situação em que o aumento contínuo do nível de formação convive com um agravamento não menos constante da taxa de desemprego entre os jovens.
\end{abstract}

Palavras-chave: Sistema educativo, desemprego, formação, políticas educativas

Associar a noção de formação à de emprego provém de uma evidência social corroborada por todos os dados estatísticos e experiências individuais. Contudo, o que é necessário dessa relação é relativamente recente. A justaposição das palavras formação e emprego é, de fato, revestida por uma força de designação que afirma como evidentes relações produzidas por ações sociais historicamente identificáveis.

O uso da expressão nominal "relação formação-emprego" espalhouse, na França, a ponto de assimilar-se a um substantivo comum que designa algo estabelecido. Para entender a força de que se reveste essa expressão e a valorização da qual é objeto, precisamos antes questionar as palavras que a compõem, assim com o hífen que as une. Assim como o termo

\footnotetext{
* Texto traduzido por Alain François. Publicado originalmente em Cahiers français № 285, 1998, pp 98-107.

** Coordenadora de pesquisa no CNRS. Universidade Paris X, França.
} 
"educação", "formação" apresenta-se hoje como um desses vocábulos necessários à comunicação em nossa sociedade. No entanto, sua utilização crescente foi concomitante a um deslocamento semântico da noção de educação para a de formação. Embora possam, às vezes, ser usadas em sentido concorrente, ambas as noções são geralmente associadas de modo indiferenciado. Observa-se um deslocamento semelhante em outros países europeus: Education and Training, na Grã-Bretanha; Ausbildung und Befursbildung, na Alemanha. Apesar de geral, este não recobre necessariamente o mesmo significado, uma vez que cada uma dessas noções designa realidades extremamente diversas. Cabe acrescentar a essa constatação a valorização da formação nos discursos políticos, institucionais e mesmo familiares. De fato, essa noção é freqüentemente associada a certas palavras-chave organizadas em pares de opostos positivos/negativos. Podemos citar: modernização, evolução versus conservadorismo e imobilismo; mudança, adaptação versus inadaptação; esquemas de cognição versus saber finito etc. Objeto de valorização, a formação está também no cerne de uma polêmica recorrente ao longo das últimas décadas.

Esses fatos opinativos exprimem a força das idéias e das crenças coletivas que sustentam a vinculação dessas duas esferas de atividades sociais separadas: relação que se objetivou na realidade social paralelamente à instauração de novos arranjos políticos e econômicos. Por esse motivo, tentaremos identificar as principais ações que vêm contribuindo para os deslocamentos mencionados e para a criação dessa relação em termos de categorias de pensamento comuns e de políticas educativas. Também mostraremos que a naturalização progressiva dessa relação contribuiu para transformar as instituições educativas, mais particularmente os colégios profissionais e técnicos (lycées professionnels et techniques), transformações cuja importância não foi devidamente avaliada. Nesse processo, procuraremos elucidar o seguinte paradoxo: embora o nível de formação dos jovens não pare de crescer na França, o acesso dessa população aos empregos está cada vez mais problemático.

\section{Evidências e paradoxos}

\section{A constituição do par formação-emprego}

A instauração de uma relação necessária entre formação e emprego veio acontecendo num período relativamente longo. Seria preci- 
so remontar ao pós-guerra para mostrar como, nos anos 50, a formação surgiu como um instrumento passível de favorecer a mudança que se procurava então: mudança nas instituições produtivas em termos de organização do trabalho bem como de relações de autoridade nas empresas, em razão da introdução do TWI (Training Within Industry) no âmbito do plano Marshall. No início dos anos 60 também foram definidas políticas de emprego que se traduziram pela criação de dispositivos e de instituições em cujo âmago estava inscrita a formação. As grandes reconversões industriais (como as que acompanharam o fechamento das minas e da siderurgia lorrena) são outros exemplos particularmente ilustrativos para observar como certas categorias de atores lograram traduzir os problemas de emprego em termos de formação e, nesse processo, fizeram ver a formação como uma resposta às necessidades, à demanda, apesar da tendência original dos principais protagonistas à hostilidade (mineiros) ou a indiferença (dirigentes de minas).

As nomenclaturas de níveis de formação

Essa vinculação entre emprego e formação encontrou sua expressão maior na planificação. É nesse âmbito que se elaboraram as nomenclaturas de níveis de formação colocando em correspondência duas distribuições hierarquizadas, a da formação por um lado, a do emprego por outro. O raciocínio que pauta essa relação de eqüivalência não se fundamenta numa projeção da ordem existente, mas numa norma a ser estabelecida. De fato, as categorizações então operadas não resultaram de uma observação, da distribuição da população empregada numa profissão de acordo com seus diplomas num dado momento, mas de relações a serem instituídas entre sistema de ensino e sistema produtivo (Affichard 1983, p. 49). Mais precisamente, essa nomenclatura construiu-se não em termos de durações ou de conteúdos de formação, mas em termos de "capacidades profissionais" supostamente produzidas por uma formação. Essa determinação por meio das condições necessárias para se ter acesso ao emprego permitia reunir na classificação assim realizada as formações adquiridas tanto no âmbito escolar como no dispositivo de formação de adultos. Entretanto, se essa codificação em níveis se manteve é porque se refere a diplomas outorgados pelo Estado cujos nomes são relativamente 
estáveis, ao contrário dos nomes de empregos sempre mais vagos e expostos a redefinições. Em outras palavras, a força e a estabilidade dessa categorização provêm de seu caráter de instrumento controlado pelo Estado. Como afirma Joëlle Affichard (1983, p. 60), esta constitui um instrumento de reconhecimento padronizado que "visa regular as condições de troca e de valorização num mercado". Elaboradas com fins técnicos, essencialmente de previsão de fluxos de populações a serem escolarizadas, essas nomenclaturas são hoje utilizadas com fins de descrição e de conhecimento da realidade social por entidades como o Cereq, o Insee (com seus "balanços formação-emprego") e, mais recentemente, pelos serviços de estudos estatísticos e de prospetiva do Ministério da Educação Nacional.

As publicações que se dedicam a mostrar as dificuldades de inserção dos jovens egressos do sistema educativo no mercado de trabalho são todas norteadas pelo procedimento que acabamos de descrever e levantam sempre o mesmo tipo de questões: será que os indivíduos ocupam os empregos para os quais se formaram? Dentro de que prazos? etc. ${ }^{1}$ Suas respostas convergem para mostrar que, dentro de uma faixa etária, os mais expostos ao desemprego são os menos diplomados. Essa constatação estatística facilita a incorporação dessa proposição nas crenças coletivas: o diploma é um fator de proteção contra o desemprego. Independentemente do indicador escolhido, taxa de desemprego ou proporção de jovens entre os desempregados, os "sem diploma" são efetivamente mais prejudicados no mercado de trabalho do que aqueles que possuem um diploma profissional (CAP, BEP), os quais também são mais prejudicados do que os que possuem um diploma de nível BTS ou DUT (cf. quadro à página 53).

Esse primeiro fato maciço e irrefutável não deveria, no entanto, ocultar outro que the é concomitante: não somente os mais diplomados estavam expostos a um risco maior de ficar desempregados em 1996 do que em 1992, como esse aumento do risco é relativamente maior do que o registrado para os menos diplomados.

Essa dupla série de tendências basta para contradizer a proposição precedente: o diploma, em si, está longe de ser uma proteção contra o desemprego, uma vez que um aumento geral dos níveis de formação não exclui um aumento geral das taxas de desemprego nessa faixa etária. Assim conseguiu-se corrigir, em meados dos anos 90, uma idéia socialmente aceita, ao constatar que o diploma é uma condição 
necessária, porém não suficiente, para se ter acesso ao emprego e que ele não "protege" do desemprego senão de modo relativo.

\section{Diplomas escolares e emprego: Relações não lineares}

O desemprego dos jovens egressos do sistema educativo só alcança sua plena significação quando relacionado a outros aspectos de sua situação no mercado de trabalho: o alongamento do período de transição entre saída da escola e ingresso num emprego com contrato de trabalho, assim como o estatuto desse emprego, sua duração (semanal ou não) e o salário recebido. Ora, em 1995, dois terços dos principiantes tinham empregos que fugiam à norma instituída no pós-guerra (contra metade em 1991); apenas $46 \%$ tinham empregos estáveis, embora muitas vezes em meio período (esses últimos representam $30 \%$ dos empregos de jovens entre 16 e 29 anos) e recebem salários reduzidos (Ponthieux 1997). Essa diminuição nos salários iniciais é geral, independentemente do nível de diploma e dos postos ocupados (operários, empregados, executivos) (Baudelot e Gollac 1997). A relação entre formação e emprego não pode, portanto, ser isolada desse conjunto de relações que definem as condições de inscrição dos jovens na massa assalariada.

Privilegiar a vinculação da formação com o emprego para dar conta das mudanças em curso, como fazem as grandes pesquisas estatísticas, eqüivale também a ocultar as desigualdades entre classes sociais perante essas mudanças. Considerar o diploma como a principal característica que determina o acesso ao emprego eqüivale a desconhecer que este atua de modo diferente segundo a pertença social, cultural (à qual está fortemente vinculado), das redes familiares ou locais etc. Esses fatos, tidos como cruciais uns 20 anos atrás, são hoje esquecidos. Esse tipo de raciocínio contém implicitamente a idéia de uma relação linear entre o valor do diploma escolar e o posto ocupado, idéia abalada, há mais de dez anos, pelo trabalho de um grupo de pesquisadores (Tanguy 1986), cujas investigações revelavam que as relações entre formação e emprego se estabelecem ao cabo de uma cadeia de mediações na forma de redes, não de relações lineares. Dessas considerações diversas concluiremos que a idéia segundo a qual a formação era inadaptada ao emprego e que essa adequação era necessária à resolução do problema, além de não ter surtido os efeitos esperados, está sendo questionada, hoje em dia, por esse 
paradoxo oriundo do mercado de trabalho: a elevação contínua do nível dos diplomas recebidos pelos jovens egressos da escola vem acompanhada por um aumento na taxa de desemprego deles. Foi, no entanto, essa idéia da educação e da formação como instrumento de ajuda para a resolução dos problemas de emprego que norteou as políticas educativas desses últimos 20 anos.

\begin{tabular}{|c|c|c|c|c|c|}
\hline \multicolumn{6}{|c|}{ Desemprego dos jovens em 1992 e 1996} \\
\hline Em 1992 & $20-24$ anos & $25-29$ anos & $\begin{array}{l}\text { Não diplomados } \\
\text { (15-29 anos) }\end{array}$ & $\begin{array}{l}\text { CAP - BEP } \\
(15-29 \text { anos })\end{array}$ & $\begin{array}{l}\text { Bac }+2 \text { e mais } \\
(15-29 \text { anos })\end{array}$ \\
\hline $\begin{array}{l}\text { Porcentagem do total de } \\
\text { desempregados }\end{array}$ & $11,7 \%$ & $10,7 \%$ & & & \\
\hline Taxa de desemprego & $20,5 \%$ & $12,5 \%$ & $25,8 \%$ & $15,1 \%$ & $7,9 \%$ \\
\hline \multicolumn{6}{|l|}{ Em 1996} \\
\hline $\begin{array}{l}\text { Porcentagem do total de } \\
\text { desempregados }\end{array}$ & $13,6 \%$ & $14,0 \%$ & & & \\
\hline Taxa de desemprego & $26,6 \%$ & $16,5 \%$ & $31,1 \%$ & $20,1 \%$ & $13,6 \%$ \\
\hline \multicolumn{6}{|c|}{ Fonte: Économie et Statistique, 1997, p. 14} \\
\hline \multicolumn{6}{|c|}{$\begin{array}{l}\text { A taxa de desemprego corresponde ao número de desempregados numa dada idade em relação ao número de ativos } \\
\text { (no sentido do BIT) da mesma idade. }\end{array}$} \\
\hline \multicolumn{6}{|c|}{$\begin{array}{l}\text { A porcentagem do total de desempregados corresponde ao número de desempregados de uma dada idade em relação } \\
\text { aos efetivos da mesma idade. }\end{array}$} \\
\hline \multicolumn{6}{|c|}{$\begin{array}{l}\text { Este quadro, portanto, se lê da seguinte maneira: se a taxa de desemprego dos jovens entre } 20 \text { e } 24 \text { anos é de } 20,5 \% \\
\text { em 1992, esses desempregados representam apenas, nessa data, } 11,7 \% \text { da sua classe de idade. }\end{array}$} \\
\hline \multicolumn{6}{|c|}{$\begin{array}{l}\text { A taxa de desemprego dá uma imagem particularmente negativa da situação dos jovens no mercado de trabalho na } \\
\text { França. Comparadas aos outros países ocidentais, as taxas de desemprego são sensivelmente mais elevadas, embora } \\
\text { a porcentagem de desempregados seja menor em razão da taxa de atividade pouco elevada, o que está em relação } \\
\text { com a alta taxa de escolarização. }\end{array}$} \\
\hline
\end{tabular}

\section{Postulados subjacentes às orientações das políticas educativas}

O ponto de vista que norteia a elaboração das políticas é o mesmo que inspira a codificação das grandes pesquisas estatísticas mencionadas acima. De fato, as nomenclaturas de formação, ferramentas elaboradas com fins técnicos de administração, pensadas em termos de níveis que anulem diferenças entretanto fundamentais entre ensino geral, técnico e profissional, impuseram-se progressivamente como categorias de percepção e de organização social; guiam as políticas do Estado, das coletividades regionais ou locais; são utilizadas pelas organizações profissionais patronais e pelos sindicatos 
de assalariados na definição de grades de classificação e também contribuem para a configuração das representações de docentes, famílias e alunos quanto a diversas formas de ensino, seus lugares e suas funções.

Das políticas educativas enunciadas em termos de níveis de ensino ou de formação...

Essas codificações foram adotadas com relativa concordância ou indiferença, embora signifiquem uma negação das propriedades constitutivas de cada forma de ensino. Essa hierarquização em termos de níveis, numa mesma escala, pressupõe, de fato, a existência de uma ordem unidimensional dos saberes, segundo a qual os saberes profissionais poderiam ser considerados como uma aplicação dos saberes técnicos, os quais seriam uma aplicação dos saberes científicos. Tal pressuposto foi veementemente questionado por autores como Georges Simondon (1969) e Paul Ladrière (1977) no tocante às relações entre ciência e técnica e por Viviane Isambert-Jamati (1990) e Jean-Pierre Darré (1984) no que diz respeito às relações entre conhecimento e ação. Essas análises, entretanto, não modificaram muito as representações sociais das diversas categorias de saberes transmitidos pela instituição escolar ou outras instituições de formação que reconhecem apenas um modelo de excelência.

As políticas educacionais e de formação inicial ou contínua impulsionadas e implementadas pelo Estado ou por autoridades oriundas dos meios profissionais inspiram-se, portanto, diretamente ou não, nessa representação da realidade em níveis. A palavra de ordem dar acesso a $80 \%$ de uma faixa etária ao nível do baccalauréat -, enunciada em 1985 é uma clara ilustração disso. A nova norma instituída pode se realizar na forma de estudos gerais, técnicos ou profissionais. De fato, a criação do baccalauréat profissional estabelece uma paridade formal entre o ensino profissional e as outras formas de ensino secundário e organiza as condições de uma revalorização desse ensino. Os movimentos de escolarização que seguiram essa política traduziram-se, no entanto, num desenvolvimento do ensino geral e num desafeto do ensino profissional como mostramos em outro artigo (Tanguy 1991). 
Geralmente enunciadas em termos de níveis de ensino ou de formação, as políticas educativas dos anos 80 também foram às vezes formuladas em termos de níveis de qualificação. É o caso da lei de 1989 que procura dar acesso a uma qualificação mínima de nível CAP ou BEP para $100 \%$ de uma faixa etária. Tal formulação subentende que a obtenção de um diploma autoriza o acesso a um posto correspondente (Bourdieu e Boltansky 1975). Revela também a força das crenças sociais na escola e a pregnância das classificações que opera. Esse enunciado, no entanto, oculta um fato importante: a qualificação foge amplamente à escola uma vez que se realiza no mercado de trabalho e a formação não é senão uma dimensão desta, entre outras, como bem mostrou Pierre Naville em 1956, num ensaio cujas principais conclusões resistiram ao tempo. A situação é bem diferente na Alemanha, onde os diplomas que sancionam uma formação dão direito a uma qualificação reconhecida e a uma inserção no emprego (Moëbus e Verdier 1997). Esse objetivo de qualificação atribuído ao sistema educativo além de operar um deslocamento da ordem escolar para a ordem das qualificações e dos empregos, coloca o nível $\mathrm{V}$ (medido pelos diplomas profissionais acima mencionados) como mínimo. A especificidade da qualificação operária vêse, assim, negada e apresentada como equivalente a uma escolarização mínima socialmente necessária, num dado momento, numa dada sociedade.

Formular as políticas educativas em termos de nível de formação ou de qualificação denota a vontade, sempre afirmada nos anos 80 , de inscrever as preocupações do emprego no cerne do sistema educativo. Analisar as categorias de pensamento que nortearam essas políticas leva, portanto, naturalmente a questionar a equação a elas subjacente, a qual estabelece relações de equivalência entre esses quatro registros diferentes da realidade: educação, formação, qualificação e emprego, equação hoje fortemente abalada pela persistência do desemprego entre os jovens, independentemente das políticas conduzidas.

\section{Os processos de decisão de criação dos diplomas profissionais: Oexemplo do baccalauréat profissional}

À primeira vista, a criação do baccalauréat profissional aparece como uma resposta à demanda oriunda da Uimm (Union des Industries 
Métallurgiques et Minières - União das Indústrias Metalúrgicas e Mineiras) e mais precisamente de um membro desta, a Fiee (Fédération des Industries Électriques et Électroniques - Federação das Industrias Elétricas e Eletrônicas), que se valeu do fato de existir um espaço de qualificação intermediário entre o dos operários (dito nível V) e o dos técnicos, para os quais uma cultura técnica geral seria necessária. ${ }^{2}$ Essa demanda, oriunda da mais poderosa organização profissional patronal, surgiu num momento em que vários diplomas coexistiam para um mesmo tipo de emprego. Ela acarretará a busca de uma resposta mais ampla, válida para todos os setores profissionais, em vez das respostas parciais e circunstanciadas que imperavam até então. Essa resposta, que emerge no âmbito de uma política escolar que institui o baccalauréat como norma, não obedece, como veremos, a qualquer necessidade econômica absoluta; atualizou-se à custa de outras respostas possíveis ao sabor de uma conjunção de fatores que precisa ser reconstituída caso a caso para os primeiros baccalauréats profissionais criados em 1985. É o que mostrou Michel Pillet (1996) a respeito do setor de carroçaria de automóveis; os fatos e argumentos a seguir provêm desse estudo.

Da diversidade das expectativas no tocante à formação das competências profissionais...

O meio profissional da carroçaria de automóveis, composto por montadoras e reparadores, é particularmente heterogêneo. As montadoras são, em sua maioria, grandes empresas com até dois mil assalariados, ao passo que as empresas de reparação são na sua maioria pequenas (com exceção das concessionárias de grandes marcas). A organização da produção e a divisão do trabalho são muito diversas nesses vários grupos e as expectativas em termos de formação de competências estão longe de ser as mesmas. Por outro lado, esses diferentes âmbitos não ocupam posições eqüivalentes perante a administração da educação nacional: as exigências dos representantes das montadoras são ouvidas com mais facilidade do que as dos reparadores.

Todo pedido de criação de um diploma profissional ou técnico requer a intervenção de agentes aptos a traduzir expectativas de competências profissionais em termos de currículo de formação. Esse trabalho de tradução cabe, majoritariamente, aos inspetores gerais do 
ensino técnico. Por sua formação e seus itinerários profissionais, que fazem deles conhecedores da indústria, assim como por sua qualidade de consultores na DLC (Direction des Lycées et Collèges - Direção dos Colégios), os inspetores gerais são os interlocutores diretos dos representantes das organizações profissionais. Por compartilharem um conjunto de pontos de vista com os representantes das grandes montadoras - uns e outros tendem, de fato, a representar o desenvolvimento técnico como um fenômeno homogêneo e linear, representação que está na base de uma classificação entre setores avançados e setores atrasados -, eles concederam espontaneamente sua preferência às montadoras em detrimento dos reparadores. A inspeção geral coloca em correspondência, portanto, dois tipos de racionalidade: a da organização técnica do trabalho adotada pelas montadoras e a do ensino técnico tal como definido pelos referenciais, dos quais são os autores. A intervenção desses inspetores gerais, com a ajuda de outras categorias de inspetores e docentes, ocorre não apenas em termos de saberes como também de inscrição numa instituição hierarquizada, na qual os meios profissionais mal percebem os princípios e as articulações. Essa inscrição num segmento do sistema escolar ocorre em virtude do estado desse sistema num dado momento. É assim que a demanda inicial de um novo diploma pelas montadoras resultou, em meados dos anos 80 , num projeto de diploma técnico.

\section{... à criação de um baccalauréat}

profissional decidido pela administração escolar

Apesar dos procedimentos regulamentares instituídos, a DLC levou, num tempo recorde, os principais representantes dessas organizações profissionais patronais a aceitar a transformação do BT (Brevet de Technicien - diploma de técnico) em baccalauréat profissional, e isso fora dos campos de consulta que reúnem todos os protagonistas interessados. Esse deslocamento de um tipo de diploma para outro, de uma instituição (o colégio técnico) para outra (o colégio profissional) ilustra bem a incapacidade dos meios profissionais em precisar a natureza dos diplomas que esperam. Essa natureza está menos relacionada aos conteúdos de ensino por eles integrados do que à posição ocupada numa ordem escolar hierarquizada. Esse exemplo mostra também que a inscrição das demandas de formação profissional 
num projeto educativo de conjunto é uma operação determinante. É essa inscrição nos âmbitos impostos por uma política escolar que confere uma forma de resposta mais ou menos apropriada a essas demandas, formas que convêm melhor a certos setores profissionais do que a outros. A conversão do Brevet de Technicien - diploma exigido, no início, de uma minoria de jovens destinados aos empregos da carroçaria - em baccalauréat profissional, que vai se tornar a norma a alcançar nos colégios profissionais, desclassificando assim os BEP e CAP no mercado escolar e no mercado de trabalho, patenteia não apenas as relações de autoridade no cerne dessas entidades de concerto representadas pelas CPC (Commissions Professionnelles Consultatives - Comissões Profissionais Consultivas), ${ }^{3}$ como também os desacordos profundos que separam o mundo da administração escolar e dos docentes, por um lado, do dos meios profissionais, por outro. Esses desacordos contribuíram à desclassificação dos titulares de um baccalauréat profissional (Veneau 1995), ao não reconhecimento desses diplomas no mercado de trabalho e à polêmica em curso quanto à relação entre escola e emprego.

\section{Codificação da formação e das atividades profissionais em termos de competências}

A vontade de racionalizar a oferta de formação em relação ao emprego é subjacente à instauração de uma pedagogia definida por seus objetivos e validada pelas competências que produz. Essa pedagogia que tende hoje a se impor nos diferentes segmentos do sistema escolar sob diferentes formas (cf. o artigo de Françoise Ropé, p. 56) forjou-se nas instituições de ensino técnico e profissional durante os anos 70 . A respeito desses ensinos, elaborou-se um conjunto de métodos, de categorizações, de nomenclaturas que norteiam, de diversas formas, o enunciado dos conteúdos de ensino, sua programação e avaliação, quando não sua transmissão. Entre eles, citaremos os referenciais de empregos e referenciais de diplomas construídos segundo um mesmo procedimento que é objeto de uma regulamentação, espécie de discurso sobre o método codificador que costumava depender de um empirismo circunstancial (Ropé e Tanguy 1994). É assim que todos os referenciais de emprego ou referenciais de atividades profissionais são elaborados com base nas mesmas rubricas: o nome do diploma; o campo de atividades; a des- 
crição das atividades baseada num conjunto de indicadores abrangendo as funções, as tarefas e as condições de exercício, elas mesmas especificadas por meio de outros indicadores. Essa preocupação em designar, nomear, descrever, buscar a exaustão, em resumo, em escapar ao não-dito, vê-se mais exacerbada ainda, uma vez que esses referenciais são supostamente ferramentas de comunicação privilegiadas entre categorias de parceiros diferentes, os agentes da instituição escolar e os representantes dos meios profissionais, particularmente, que intervêm na concepção e na elaboração do diploma.

Os referenciais de diplomas...

Os referenciais de diplomas são de fato definidos e elaborados com base nos referenciais de emprego e definem, supostamente,

as competências esperadas para exercer uma atividade no setor profissional em questão e as condições nas quais estas devem ser avaliadas (...). [Eles são] o suporte principal da avaliação das aquisições para conferir o diploma, em formação inicial tanto quanto em formação contínua. (MEN 1991, p. 10)

Em outras palavras, o referencial de diploma é concebido como uma ferramenta que permite criar uma correspondência estreita entre a formação e a distribuição das atividades profissionais. Essa busca de eficiência, na adequação ao emprego, mobiliza um conjunto de procedimentos, de codificações fundamentados numa lógica dedutiva cuja compreensão requer que se fixe o campo semântico das noções utilizadas nesse dispositivo técnico. Todo referencial de diploma começa, portanto, por enunciar a competência global visada (em termos de "ser capaz"); a seguir, as capacidades gerais implicadas nessa competência global, geralmente expressas por quatro verbos de ação ou seus sinônimos: (ser capaz de) informar-se, organizar, realizar, comunicar; a seguir, as capacidades e competências terminais e, finalmente, os saberes e know-how a elas associados. Além desse conjunto de procedimentos, os referenciais de diplomas apresentam-se de saída na forma de quadros que vinculam, por um lado, as principais funções e atividades descritas no 
referencial do emprego com as capacidades e competências terminais; por outro lado, as competências terminais com os saberes e know-how tecnológicos associados. Essa codificação dos diplomas de ensino técnico e profissional, operada com base em "descritores", fundamenta-se, em última instância, numa lista de know-how, unidades de base dessa ordenação técnica, elas próprias definidas por uma série de relações de encaixe. Em outras palavras, esse método pressupõe a existência de um campo de referência que se deixe representar como um conjunto finito de elementos passíveis de descrição. Pressupõe também que relações de implicação possam ser estabelecidas entre realizar uma tarefa, dispor da competência idônea e saber realizar essa tarefa; tantas relações que, como mostrou Marcelle Stroobants (1993), elas permanecem eminentemente problemáticas.

\section{...racionalização e indeterminação}

Essa conformação técnica das expectativas e dos resultados da formação encontra sua justificativa no papel atribuído ao referencial de diploma, "um contrato" entre os alunos, os formadores e os empregadores. A "autoridade" dada à metodologia é vista como uma garantia de cientificidade, de eficiência e também de eqüidade. Entretanto, o dispositivo assim realizado constitui apenas, segundo a opinião mesma daqueles que contribuíram ativamente para sua elaboração, um quadro para o docente e não deveria ser assimilado a um programa. Cabe ao docente transformar essas listas de tabelas num conjunto integrado e operar a síntese que todo ensino constitui por natureza.

Paradoxalmente, essa busca de adaptação às configurações de emprego transformou-se no seu contrário: a formalização em busca de uma transparência gerou abstração e opacidade. A procura por flexibilidade e adaptabilidade propiciou rigidez e "replicação". Esse tipo de racionalização implementado, apoiado em procedimentos de objetivação da realidade, contrasta singularmente com a incerteza e a imprevisibilidade características dos movimentos de empregos, por um lado, e com a indeterminação ligada aos fenômenos ditos de "competências", por outro. Finalmente ressaltaremos que a revisão periódica dos diplomas profissionais e técnicos (a cada quatro anos) garante supostamente a adaptação ao emprego e ocorre no âmago do quadro hierárquico 
que ordena o conjunto dos diplomas profissionais e técnicos participando de um mesmo campo profissional, abrangendo do CAP ao BTS e ao DUT. Esse quadro é, portanto, considerado como um dado que permanece intocado durante um tempo relativamente longo. Essa estabilidade da hierarquia dos diplomas pode ser interpretada como a expressão de um compromisso quanto à divisão social do trabalho existente entre a categoria dos técnicos (superiores ou não) e a categoria dos operários (qualificados ou não). ${ }^{4}$

\section{Uma busca contínua de aproximação entre as instituições educativas e as empresas}

A valorização da alternância...

Uma das maiores mudanças ocorridas durante esses 20 últimos anos parece mesmo ser a implementação de um conjunto de práticas diversas, embora todas designadas com o nome de alternância. Esse termo subsume as práticas que buscam uma cooperação entre as instituições de formação (escola ou organismos especializados com estatutos variados, públicos ou privados) e as empresas. Essa ação conjugada de duas entidades sociais, de resto separadas, é afirmada como um princípio que comanda tanto a redefinição dos modos de formação adquiridos na escola quanto a organização do dispositivo de inserção dos jovens (com o qual "a formação em alternância" é às vezes erroneamente identificada). Proclamado com essa ênfase característica das sociedades modernas, esse princípio não é tão novo quanto se pensa. Os estatutos dos centros de aprendizagem do pósguerra (instituição escolar que está na base dos colégios profissionais na França) Ihes permitiam, de fato, assinar convênios com as instâncias profissionais patronais e as coletividades locais, inaugurando assim uma forma do que hoje se costuma chamar de alternância.

Contudo, o envolvimento das empresas no processo de formação vai diminuir durante os anos 60 e 70, correlativamente à extensão da escolarização. Por isso, a aproximação escola-empresas, considerada como uma das maiores mudanças ocorridas no sistema escolar francês, é apresentada e percebida sob a perspectiva da novidade. Essa aproximação ocorre por iniciativa do Estado e de organismos internacionais como a OCDE e a CEE. 
Essa aproximação ocorre de diversas formas: pela criação de seqüências educativas em empresas (em 1979) para os alunos preparando uma formação profissional destinada aos empregos de operário e empregado (diplomas CAP e o BEP); pela implementação de convênios escola-empresas (1985) e de uma instância, o Haut Comité EducationEconomie (Alto Comitê Educação-Economia, 1986) cuja função é estabelecer um concerto permanente no mais alto nível entre a educação nacional e os parceiros econômicos. A criação, em 1986, do currículo que conduz ao baccalauréat profissional, o qual integra períodos de 12 a 24 semanas em empresas, é apresentada como uma realização notável da cooperação procurada. Em 1992 (lei do 17 de julho), o princípio dos estágios em empresas é estendido a todas as formações, levando a diplomas ou títulos de ensino profissional ou técnico (BTS, DUT, graduações em ciências e técnicas). Legitimava-se, assim, o papel da empresa na formação.

\section{...e no dispositivo de inserção profissional}

O princípio de alternância também é invocado para designar a organização do dispositivo de inserção profissional. Sob a égide do Ministério do Trabalho e inscrito no quadro jurídico e administrativo da formação contínua, esse dispositivo apresenta-se como um conjunto de arranjos institucionais eminentemente instáveis; as formas sucessivas de que se revestiu são uma ilustração eloqüente disso.

Entretanto, todas se fundamentam na idéia de um estágio em empresas associado a uma formação no cerne de uma instituição habilitada. Assim descrita, essa forma de alternância é a imagem invertida da precedente, uma vez que se baseia na primazia conferida à empresa. Na verdade, as funções atribuídas a uma ou à outra, nesse caso, não são muito explicitadas nem objeto de regulamentações. As normas que regem os estágios em empresas e as ações de formação nas instituições permanecem fracas e se limitam, no melhor dos casos, a determinar o tempo de aprendizagem fora das situações de trabalho. A implementação da alternância é aqui justificada como uma via de acesso ao emprego ou à qualificação. 
É o caso das duas formas ainda em uso hoje: o contrato de qualificação e o contrato de adaptação, que favoreceram respectivamente 246.851 e 103.094 jovens em $1994 .^{5}$ Inicialmente destinadas ao jovens egressos do sistema educativo sem diplomas, essas ações dirigem-se hoje de modo preferencial a um público cada vez mais velho e cada vez mais diplomado, o que revela uma seletividade aumentada pela perenização do desemprego entre os jovens.

Uma política de restauração da aprendizagem

Concomitantemente, a aprendizagem, modo de formação mais antigo instituído para preparar às profissões de operário, é objeto de repetidas intervenções políticas no intuito de deter seu declínio e de estendê-la à preparação das profissões executivas e de concepção (técnicos e engenheiros). Em 1994, havia 340 mil jovens em aprendizagem, entre os quais $73 \%$ preparavam um CAP. ${ }^{6} \mathrm{Na}$ mesma época, os colégios profissionais e técnicos reuniam 1.047 .325 jovens, entre os quais $33 \%$ preparavam um BTS ou um DUT (Le Roux 1997).

A forma escolar continua, portanto, predominante na França. Não se deve, contudo, subestimar o alcance das ações do Estado com o apoio das organizações profissionais patronais. Elas geraram profundas mudanças no estatuto e no funcionamento das instituições e, correlativamente, nas práticas educativas e nos âmbitos de percepção de seus agentes.

Ação de formação e tratamento social do desemprego

Essas mudanças, quando confrontadas com a instauração de um dispositivo de inserção dos jovens, podem ser consideradas como uma política de adaptação da formação ao emprego, por meio do deslocamento de parte das aprendizagens para os locais de trabalho. Também exprimem o caráter co-extensivo das políticas de formação e das políticas do emprego, sendo as primeiras, no final das contas, o elemento principal das segundas. Com o tempo, muitas dessas ações aparecem de fato como um modo de tratamento do desemprego dos jovens pelo Estado, 
aval da coesão e da integração sociais. Tudo ocorre como se, por não se poder reconhecer o direito ao trabalho a todos os jovens, estes se vissem oferecer o direito a um lugar na fila de espera onde lhes são oferecidas as condições de manutenção e de aquisição das qualidades requeridas para ter acesso a um emprego. A ambigüidade dessas ações explica por que a concordância social na qual essas políticas parecem elaborar-se e aplicar-se não tenha logrado impedir a polêmica que perdura na cena pública, em torno da idéia de inadaptação da formação ao emprego.

\section{Conclusão}

Uma instrumentalização maior do sistema educativo

Todo sistema educativo preenche simultaneamente várias funções: socialização das novas gerações, transmissão dos saberes e da cultura, preparação dos indivíduos para ocupar um lugar na divisão social e técnica do trabalho etc. Estas são ordenadas segundo uma hierarquia que oscila de acordo com os momentos históricos. As tensões inerentes ao cumprimento dessas diferentes funções e a sua ordenação são objeto de disputas recorrentes. A ênfase dada às funções instrumentais do sistema educativo traduz-se por esse deslocamento da noção de educação para a de formação e de qualificação, observada tanto na linguagem cotidiana quanto no enunciado das políticas. Essa inflexão na orientação, preconizada há 30 anos pela OCDE, foi então qualificada de "catastrófica" por Dahrendorf que lembrava que o sistema educativo há de ser, antes de mais nada, "um lugar onde se elabora a racionalidade cognitiva de uma sociedade moderna" (Krais 1995).

A busca de uma relação de correspondência entre formações técnicas/profissionais e o perfil dos empregos também encerra tensões inevitáveis, uma vez que essas formações devem permitir ao mesmo tempo a adaptação aos empregos existentes no momento presente e a adaptabilidade a configurações de empregos num futuro mais ou menos próximo. Esse tipo de tensões recebe respostas diversas em cada país. Na Alemanha, onde a formação profissional se inscreve nas empresas, essa tensão se resolve pela organização de um processo de formação que se especializa progressivamente ao longo dos anos de aprendizagem. Na França, 
onde a formação inicial ocorre essencialmente na instituição escolar, essa tensão se resolve por uma antecipação do futuro, representada pelas de formas de organização do trabalho existentes nas grandes empresas. Esse tipo de racionalização erigida em norma opõe-se, contudo, principalmente às formas existentes na maioria das pequenas e médias empresas. Também a polêmica em torno da inadequação da formação continua a se desenrolar na cena pública.

A crença na formação como instrumento de resolução dos problemas do emprego está na base do dispositivo de inserção social e profissional dos jovens. Quase duas décadas de persistência do desemprego destes revelam, contudo, que, para essa população, a formação era antes um substituto do emprego, uma senha numa fila mais ou menos comprida. No final das contas, a translação para cima operada em matéria de educação e de formação com fins de ajuste ou de antecipação dos movimentos do emprego teve por efeito o de intensificar a concorrência no mercado de trabalho entre categorias de diplomados avaliadas de acordo com o nível de seus diplomas e não de acordo com suas competências efetivas.

\section{O mito da racionalização única}

Ao cabo dessa reflexão, parece-nos possível afirmar que a substantificação da vinculação desses dois campos de atividades sociais, educação e formação, por um lado, com o emprego, por outro, no modo de relações lineares e necessárias, substantificação traduzida pela expressão nominal "relação formação-emprego", fundamenta-se num consenso por defeito. De fato, emerge antes como uma ideologia de nosso tempo - no sentido que K. Manheim confere a essa noção -, uma vez que garante ao mesmo tempo funções de integração social, de legitimação e de dissimulação de uma ordem social existente. Mas oculta as mudanças que ocorrem nas relações salariais, mudanças que se manifestam, hoje em dia, com uma acuidade maior entre as populações de jovens que se iniciam no mercado de trabalho.

Por isso, pareceu-nos necessário mostrar que o recurso exacerbado à educação e à formação para resolver problemas de emprego não diz respeito à necessidade contida no substantivo "relação formação-emprego", mas a um conjunto de ações, acontecimentos, decisões que privilegiaram essa orientação em detrimento de outras possíveis. 
Essa interpretação, que rompe com o positivismo das análises conduzidas em termos de racionalização e de modernização, permite revelar que, em todas as situações, diversas racionalidades se confrontam. Cabe aos pesquisadores mostrar que essa noção de racionalidade se declina no plural e "repelir o mito" de uma racionalização necessária e universal.

\section{Notas}

1. As grandes pesquisas estatísticas são norteadas, em cada país, por características nacionais. Assim, na Grã-Bretanha, as pesquisas enfocam grupos de uma determinada idade, uma vez que este é o principal fator de estruturação do sistema educativo. A isso se acrescentam o enunciado dos direitos e das garantias em termos de idade, a utilização da idade nos debates políticos e, mais geralmente, a tradição de uma interrupção precoce dos estudos e a expectativa de um ingresso rápido no mercado de trabalho, fatos que indicam o papel da idade na estrutura social (ageing structures)

2. Essa demanda foi formulada a respeito do perfil do "técnico de ateliê", categoria que surge nas grades de classificação da metalurgia em 1975. A resposta, trazida em 1985, entretanto, nada tinha de necessário uma vez que, para todas essas questões levantadas desde o início dos anos 80, A. Prost e seu grupo de trabalho excluíam um planejamento da oferta de formação por nível ao mesmo tempo em que sublinhavam a diversidade de qualificações em uso no sistema produtivo e as dificuldades relacionadas à previsão de suas evoluções. "Nesse campo - dizia ele - os interesses sociais pesam mais, em geral, do que a racionalidade técnica". Ponto de vista confirmado pelas conclusões de uma comissão encarregada de examinar a receptividade da demanda da Uimm com base numa análise da ocupação de empregos nos principais setores industriais.

3. "As Comissões Profissionais Consultivas (CPC) -

A criação dos CAP em nível nacional, decidida após a Liberação, foi acompanhada pela instauração de um dispositivo de concerto entre o Ministério da Educação Nacional e os parceiros sociais. Assim, foram criadas as comissões nacionais profissionais consultivas (decreto de 1948) que se transformariam, em 1972, nas Comissões Profissionais Consultivas (CPC). Seu número máximo foi fixado em 20 e elas correspondem às principais atividades econômicas reconhecidas (a comissão no 1 tem sede no Ministério da Agricultura). Constituem um lugar de consulta obrigatória para a elaboração de todos os diplomas de ensino técnico e profissional (do CAP ao BTS). (...) O papel mais importante das CPC é o de se pronunciarem duas vezes a res- 
peito de todo projeto de criação, de modificação ou de supressão de diplomas tecnológicos ou profissionais:

uma primeira vez do ponto de vista da oportunidade: é ou não preciso criar tal novo diploma, empreender uma modificação em tal ou tal direção, suprimir tal diploma?;

uma segunda vez do ponto de vista do diploma em si, para aprovar seu conteúdo definitivo.

Existem atualmente, no Ministério da Educação Nacional, 17 Comissões Profissionais Consultivas encarregadas de acompanhar aproximadamente 650 diplomas, o número dos diplomas variando muito conforme a configuração do campo profissional recoberto pela CPC (entre 20 e 170, para a metalurgia)." - Trechos escolhidos pela redação dos Cahiers français da obra de Benoît Bouyx, L'enseignement technologique et professionnel. Paris: La Documentation française/Centre national de documentation pédagogique, 1977, pp. 67-68.

4. Esse modo de fazer opõe-se àquele utilizado na Alemanha, onde a oportunidade de proceder a reformas é ela mesma objeto de discussões e de negociações e onde a decisão diz respeito ao conjunto das formações existentes. Sem dúvida, deve-se ver nisso a expressão das diferenças existentes na relação entre formação e qualificação, por um lado, e na divisão social do trabalho, por outro. Na Alemanha, os diplomas que sancionam uma formação dão direito, como já dissemos, a uma qualificação reconhecida e a uma inserção no emprego; o sistema profissional oferece aos operários a possibilidade de ter acesso, após adquirirem uma certa experiência, a postos de técnicos (Moëbus, Verdier 1997).

5. Método de cálculo: total no fim do ano de 1993 ao qual é acrescido o fluxo de ingresso em 1994. Sabendo-se que um jovem aproveita em média 1,3 ação, pode-se considerar que esses números superestimam em aproximadamente $1 / 3$ o número de indivíduos (Le Roux 1997).

6. Esse número representa, ele também, o total de aprendizes em 31 de dezembro de 1993 (Le Roux 1997).

\section{From Educational System to Employment. Upbringing: A Uni- versal Benefit?}

ABSTRACT: Since the 50s, the relation between upbringingemployment has forced itself progressively into the main principle from educational policies, causing changes into the technical teaching field. The author refuses the evidence on this relation, its progressive naturalization and foster to understand the paradox from a situation in which the ongoing increase of the upbringing level lives with a worsening not less steady of the unemployment rate between youngsters. 


\section{Bibliografia}

AFFICHARD, Joëlle. "Nomenclatures de formation et pratiques de classement". Formation-emploi, no 4. Paris: La Documentation Française, 1983.

BAUDELOT, Christian e GOLLAC, Michel. "Le salaire du trentenaire; question d'âge ou de génération". Économie et Statistique, no 304305, 1997, pp. 17-35.

BOURDIEU, Pierre e Boltansky, L. "Le Titre et le poste: Rapports entre le système de production et le système de reproduction". Actes de la Recherche en Sciences Sociales, № 2, 1975, pp. 95-107.

DARRÉ, Jean-Pierre. La parole et la technique. Paris: L'Harmattan, 1985.

ISAMBERT-JAMATI, Viviane. Les savoirs scolaires. Paris: Éditions Universitaires, 1990.

KRAIS, Beate. "Trente ans de sociologie de l'éducation: Problématiques et controverses". In: JOBERT, Annette; MARRY, Catherine e TANGUY, Lucie, Éducation et travail en Grande-Bretagne, Allemagne et Italie. Paris: Armand Colin, 1995, pp. 48-64.

LADRIÈRE, Paul. Les enjeux de la rationalité. Le défi de la science et de la technologie aux cultures. Paris: Aubier-Unesco, 1977.

LE ROUX, Annie. "Panorama de la formation professionnelle des jeunes en France et à l'étranger". Éducation et Formation, № 49, 1997, pp. 89-105.

MINISTÈRE DE L'ÉDUCATION NATIONALE. "Direction des Lycées et Collèges". Documents méthodologiques, le référentiel des activités professionnelles. Paris, 1991.

MOËBUS, Martine e VERDIER, Éric (orgs.). Les diplômes professionnels en Allemagne et en France. Paris: L'Harmattan, 1997.

PILLET, Michel. "La création du baccalauréat professionnel". Formationemploi, № 52. Paris: La Documentation Française, 1995.

PONTHIEUX, Sophie. "Débuter dans la vie active au milieu des années quatre vingt dix: Des conditions qui se dégradent". Économie et Statistique, no 304-305, 1997, pp. 37-41. 
PROST, Antoine. Les lycéens et leurs études. Paris: Ministère de l'Éducation Nationale, 1983.

ROPÉ, Françoise e TANGUY, Lucie (orgs.). Savoirs et compétences. De l'usage de ces notions dans l'école et l'entreprise. Paris: L'Harmattan, 1994.

SIMONDON, Georges. Du mode d'existence des objets techniques. Paris: Aubier-Montaigne, 1969.

STROOBANTS, Marcelle. Savoir-faire et compétences au travail, une sociologie de la fabrication des aptitudes. Bruxelas: Éditions de l'Université de Bruxelles, 1993.

TANGUY, Lucie (org.). L'introuvable relation formation-emploi, un état des recherches en France. Paris: La Documentation Française, 1986.

VENEAU, Patrick. "Des objectifs à la réalité, les baccalauréats professionnels". Formation-emploi, no 50. Paris: La Documentation Française, 1995. 